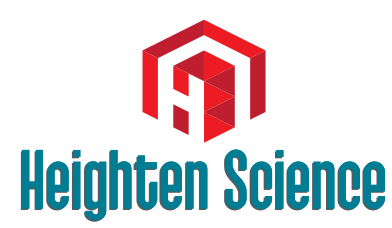

P U B L I C A T I O N S Corporation

\title{
Successful Therapy with intravenous gamma globulin in two children with postinfectious bronchiolitis obliterans
}

\author{
Sevgi Pekcan ${ }^{1}$, Bahar Gökturk²* and Ismail Reisli ${ }^{3}$ \\ ${ }^{1}$ Necmettin Erbakan University Meram Faculty, Department of Pediatrics, Division of Pediatric \\ Pulmonology, Konya, Turkey \\ 2Baskent University Faculty of Medicine, Department of Pediatrics, Division of Pediatric Allergy \\ and Immunology, Konya, Turkey \\ ${ }^{3}$ Necmettin Erbakan University Meram Faculty, Department of Pediatrics, Division of Pediatric \\ Allergy and Immunology, Konya, Turkey
}

\begin{abstract}
*Address for Correspondence: Dr. Bahar Gokturk, Baskent University Faculty of Medicine, Department of Pediatrics, Division of Pediatric Allergy and Immunology, 42080, Hocacihan Mahallesi, Saray Caddesi, Selcuklu, Konya, Turkey, Tel :+90 332 2570606, Fax: +90 332 2570637; Email: gokturkbahar@yahoo.com

Submitted: 26 May 2017

Approved: 22 June 2017

Published: 23 June 2017

Copyright: @ 2017 Pekcan S. This is an open access article distributed under the Creative Commons Attribution License, which permits unrestricted use, distribution, and reproduction in any medium, provided the original work is properly cited
\end{abstract}

Bronchiolitis obliterans (BO) is an infrequent clinical syndrome characterized by the chronic obstruction of small airways due to fibrosis [1]. Intravenous immunoglobulin (IVIG) could be used for treatment while underlying immune mechanisms in the pathogenesis of BO exist [2]. Here, we present two children with BO due to adenovirus infection whose complaints resolved after IVIG replacement.

\section{CASE 1}

A 21 month-old boy was admitted with the complaints of hacking cough, wheezing, difficulty in breathing for 4 months. From the history; he needed mechanical ventilation due to a severe adenoviral pneumonia (adenovirus PCR was positive on nasal swab), was diagnosed as bronchiolitis obliterans (BO), $1 \mathrm{mg} / \mathrm{kg}$ methylprednisolone was continued for 4 weeks, was discharged to home with oxygen replacement, and hospitalized 5 more times in a 4 month period. His weight was 10600gr (10-25p), height was $83.5 \mathrm{~cm}(25 \mathrm{p})$. On physical examination, there were tachpnea, central cyanosis, bilateral rales and rhonchi. Chest computerized tomography demonstrated mosaic pattern and ground glass opacities. Immunodeficiency, cystic fibrosis, allergic hypersensitivity and tuberculosis were excluded (Data not shown). Methylprednisolon treatment $(1 \mathrm{mg} / \mathrm{kg} / \mathrm{day})$ was restarted, but he had to be hospitalizated for three times during reduction period of steroid. Steroid dosage had to be increased during hospitalizations. Azithromycin prophylaxis was started 3 times a week during reduction period of steroid, and continued for 5 months, but clinical improvement could not be achieved. Angiotensin converting enzyme inhibitor was started while his pulmonary artery pressure was $29 \mathrm{mmHg}$. The family was convinced to move to another house due to intense moisture and mould. While clinical improvement couldn't be achieved, intravenous immunoglobulin G (IVIG) replacement every 3 weeks for a dose of $400 \mathrm{mg}$ / kg was started when he was 30 month-old. During 6 doses IVIG replacement, only one hospitalization was needed at winter time, and his need for oxygen was disappeared. The replacement of IVIG was stopped when he was 35 month-old. After termination of IVIG replacement, he was hospitalized for 2 times when he was 38 and 40 month old, so IVIG replacement was given for 3 times more. He is now 72-month old, takes inhaled corticosteroids, azithromycine propylaxis for 6 months in a year. He has no cough, tachypnea, exercise intolerance, rales, and need for oxygen anymore. The last pulmonary artery pressure was detected as $20 \mathrm{mmHg}$. His body weight: $16.5 \mathrm{~kg}(50$ 75p), height: $104 \mathrm{~cm}$ (75p). Radiological imagings were shown in figure 1. 


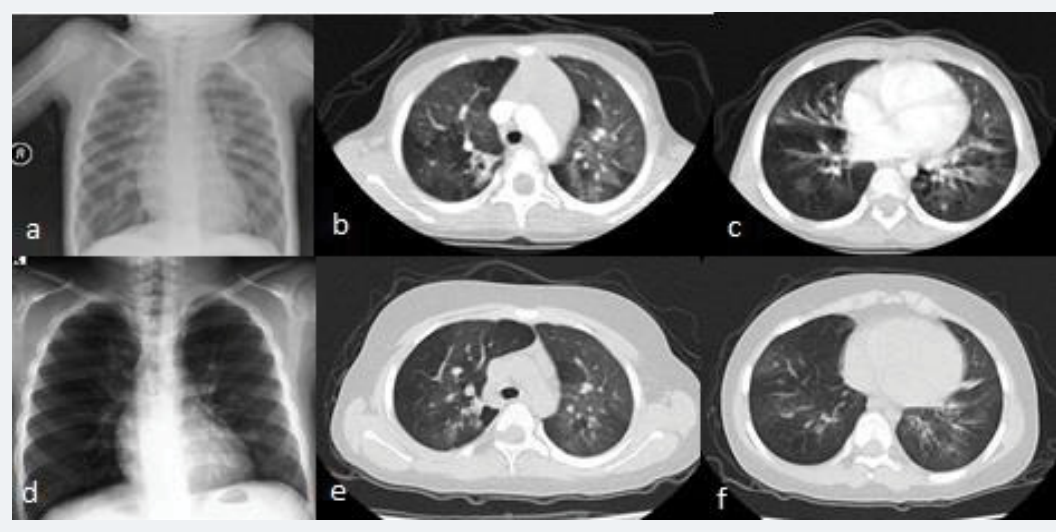

Figure 1: Posteroanterior chest X-ray and chest computerized tomography $(a, b, c)$ demonstrated mosaic attenuation pattern and ground glass opacities with areas of hypo- or avascularity before treatment. Radiological abnormalities almost recovered after treatment $(d, e, f)$.

\section{CASE 2}

A 4 month-old boy was admitted with the complaints of cough, wheezing, difficulty in breathing for 2 months after Influenza-A ve Respiratory syncytial virus-B bronchiolitis. From the history; maternal smoking was present. On physical examination, there were tachpnea, central cyanosis, whezing, bilateral rhonchi. Immunodeficiency, cystic fibrosis, allergic hypersensitivity and tuberculosis were excluded (Data not shown). Chest computerized tomography demonstrated mosaic pattern and ground glass opacities. Inhaled budesonide, oral methylprednisolone $(1 \mathrm{mg} / \mathrm{kg} / \mathrm{day})$, gastroeosofageal reflux treatment were started. Oral steroid was continued for two weeks and stopped after a reduction period. But the symptoms reappeared. He had totally 2 months oral methyprednisolon treatment until he reached 7.5 months old and had to be hospitalized for after every cessation period of steroid. Subcutaneous immunglobulin G (SCIG) replacement was started $(0.12 \mathrm{mg} / \mathrm{kg} /$ dose every week) when he was 7.5 month-old. He is now 10 month-old and he never needed systemic corticosteroid treatment and hospitalization after SCIG replacement. His complaints revealed totally and he needed inhaled corticosteroid intermittantly.

Bronchiolitis obliterans (BO) is a severe form of chronic obstructive lung disease that results from an insult to the lower respiratory tract [3]. The clinical scenario consists of chronic respiratory symptoms for more than 4 to 8 weeks in a previously healthy child that occur after an episode of a severe acute respiratory infection. Patients present with decreased pulmonary compliance, increased airway resistance, elevated air trapping, and, in general, poor or no response to bronchodilators. Adenovirus has been identified as a cause of post infectious BO (PIBO) in up to 50\% of the cases [3].

The treatment for BO has not been definitely established in the literature. The treatment protocol for PIBO included oral prednisone and azithromycin [4]. Li et al showed that treatment with corticosteroids and azithromycin was effective in $85.7 \%$ of cases [3]. Oral corticoids can be given in divided doses of $1-2 \mathrm{mg} / \mathrm{kg} /$ day, four weeks later the dose is gradually decreased to a single early morning dose of $0.5 \mathrm{mg} / \mathrm{kg} / \mathrm{day}$, and the total course of steroids is 6 months. There are reports of beneficial effects of pulse therapy with methylprednisolone $(10 \mathrm{mg} / \mathrm{kg} /$ day or $25-30 \mathrm{mg} /$ day, maximum $1 \mathrm{gr}$, IV bolus 3 days/month totally 6 cures) in the initial phases of the PIBO, before fibrosis is established [5]. High doses of inhaled steroids can also be administered. In the most severe cases of lung damage, a lung transplant may be the best recourse $[1,3]$.

Azitromycine is amodulator of neutrophil activity. It supresses chemotaxis in inflammatory region, acts as an anticytokine by inhibiting IL-8, IL-1 $\beta$, IL-6, TNF $\alpha$, prostaglandin, and even improves pulmonary function [6,7]. Azithromycin is given 
orally at $5 \mathrm{mg} / \mathrm{kg} /$ day, once daily for 3 consecutive days per week, or $10 \mathrm{mg} / \mathrm{kg} /$ day, every other day (3 times a week) for 6 months [6]. Based on these recommendations we also administered azithromycine $10 \mathrm{mg} / \mathrm{kg} 3$ times a week in winter time to our patient.

Some current treatments were based on the aim to control the inflammation because of the role of the immunological response in the physiopathology of this disease. Mycophenolate mofetil, sirolimus, IL-2 receptor antibodies, inhaled cyclosporine A, cyclophosphamide, plasmapheresis, statin, thalidomide, alentuzumab (anti-CD52 antibody), tumor necrosis factor antagonists are other treatment choices specifically used for BO developed after bone marrow transplantation which were reported usually in case reports [8]. Almost all the treatment modalities tried till now can cause secondary immunodeficiency and none of them could achieve satisfiying results. So we tried an alternative treatment modality which can be supposed as a safe one. The empirical monthly administration of IVIG has been used as a treatment option only in one case who had a favorable response to IVIG infusions and a 3-day regimen of pulse IV methylprednisolone (30 mg/kg per daily dose), both given monthly for 6 months [2]. The pathological findings of our patients also resolved after IVIG replacement treatment, too. Although it is hard to decide for which patients IVIG is an optimal treatment choice, we suggest that it can be used before the other immunosupressive treatment modalities other than corticosteroids.

The precise mechanism by which IVIG suppresses harmful inflammation has not been definitively established. The massive quantity of antibodies may stimulate the host's complement system, leading to enhanced removal of all antibodies, including the harmful ones. Intravenous immunglobulin $\mathrm{G}$ also blocks the antibody receptors on immune cells (macrophages), leading to decreased damage by these cells or regulation of macrophage phagocytosis. Immunoglobulin binds to the Fc receptors on surfaces of $\mathrm{B}$ and $\mathrm{T}$ cells, prevents entrance of antigen to the cell and antibody response, so immunomodulation effect occurs [9]. Anti-inflammatory effect is by decreasing the cytokinesand other proinflammatorymediatorsreleasedfrom monocyte/macrophages. IL-6, IL-8, IL-1Ra, TNF-alfa, IL-2, IL-10, interferon $\gamma$ (IFN $\gamma$ ) ve tumor necrosis factor (TNFb) levels decrease significantly after IVIG infusion [10]. Improvement can be achieved in our patients with one or more of these mechanisms. While only three cases reported including ours are not enough to insist on the effectiveness of IVIG for BO, further studies are necessary in order to decide whether IVIG could be an alternative choice for $\mathrm{BO}$ and for which patient groups it can be chosen.

\section{SUMMARY}

In conclusion, early diagnosis and treatment, and avoidance of repeated respiratory tract infection may be helpful to improve the prognosis. We suggest that intravenous or subcutaneous immunglobulin G treatment may offer some benefit for PIBO patients by decreasing the number and severity of infections, and its immunomodulatory effects.

\section{ACKNOWLEDGMENTS}

There are no sources of support in the form of grants, equipment, or drugs, including any funding received for this work from any organizations.

\section{AUTHORSHIP AND CONTRIBUTORSHIP}

Sevgi Pekcan is responsible for writing the article. Bahar Gokturk is responsible for writing and correcting the article. Ismail Reisli is responsible for correcting the article.

\section{REFERENCES}

1. Champs NS, Lasmar LM, Camargos PA, Marguet C, Fischer GB, et al. Post-infectious bronchiolitis obliterans in children, J. Pediatr (Rio J). 2011; 87: 187-198. Ref.: https://goo.gl/7kT6cA

2. Kim CK, Kim SW, Kim JS, Koh YY, Cohen AH, et al. Bronchiolitis obliterans in the 1990s in Korea and the United States. Chest. 2001; 120: 1101-1106. Ref.: https://goo.gl/H7qkaB 
3. Li YN, Liu L, Qiao HM, Cheng H, Cheng HJ. Post-infectious bronchiolitis obliterans in children: a review of 42 cases. BMC Pediatr. 2014; 25: 238. Ref.: https://goo.gl/CgmyWf

4. Meyer KC, Raghu G, Verleden GM, Corris PA, Aurora P, et al. An international ISHLT/ATS/ERS clinical practice guideline: diagnosis and management of bronchiolitis obliterans syndrome. Eur Respir $\mathrm{J}$. 2014; 44: 1479-1503. Ref.: https://goo.gl/fdVnR1

5. Moonnumakal SP, Fan LL. Bronchiolitis obliterans in children. Curr Opin Pediatr. 2008; 20: 272-278. Ref.: https://goo.gl/RkMPiQ

6. Yates B, Murphy DM, Forrest IA, Ward C, Rutherford RM, et al. Azithromycin reverses airflow obstruction in established bronchiolitis obliterans syndrome. Am J Respir Crit Care Med. 2005; 172 : 772-775. Ref.: https://goo.gl/heaBa5

7. Verleden GM, Vanaudenaerde BM, Dupont LJ, Van Raemdonck DE. Azithromycin reduces airway neutrophilia and interleukin-8 in patients with bronchiolitis obliterans syndrome. Am J Respir Crit Care Med. 2006; 174: 566-570. Ref.: https://goo.gl/h3bzJR

8. Hayes D Jr. A review of bronchiolitis obliterans syndrome and therapeutic strategies. J Cardiothorac Surg. 2011; 6: 92. Ref.: https://goo.gl/NySiqB

9. Nimmerjahn F, Ravetch JV. The antiinflammatory activity of IgG: the intravenous IgG paradox. J Exp Med. 2007; 204: 11-15. Ref.: https://goo.gl/pzNGSE

10. Ibáñez $C$, Suñé $P$, Fierro $A$, Rodríguez $S$, López $M$, et al. Modulating effects of intravenous immunoglobulins on serum cytokine levels in patients with primary hypogammaglobulinemia. BioDrugs. 2005; 19: 59-65. Ref.: https://goo.gl/xHN12R 